\title{
Vigny, une ironie romantique? dir. S. Ledda et S. Vanden Abeele-Marchal
}

\section{Patrick Mérope}

\section{(2) OpenEdition}

1 Journals

\section{Édition électronique}

URL : http://journals.openedition.org/studifrancesi/10664

DOI : $10.4000 /$ studifrancesi. 10664

ISSN : 2421-5856

Éditeur

Rosenberg \& Sellier

\section{Édition imprimée}

Date de publication : 1 décembre 2017

Pagination : 562-563

ISSN : 0039-2944

\section{Référence électronique}

Patrick Mérope, «Vigny, une ironie romantique? dir. S. Ledda et S. Vanden Abeele-Marchal », Studi

Francesi [En ligne], 183 (LXI | III) | 2017, mis en ligne le 01 février 2018, consulté le 22 janvier 2021.

URL : http://journals.openedition.org/studifrancesi/10664; DOI : https://doi.org/10.4000/

studifrancesi. 10664

Ce document a été généré automatiquement le 22 janvier 2021.

\section{(c)}

Studi Francesi è distribuita con Licenza Creative Commons Attribuzione - Non commerciale - Non opere derivate 4.0 Internazionale. 


\title{
Vigny, une ironie romantique? dir. S. Ledda et S. Vanden Abeele-Marchal
}

\author{
Patrick Mérope
}

\section{RÉFÉRENCE}

Vigny, une ironie romantique?, «Bulletin de l'Association des Amis d'Alfred de Vigny» 1, nouvelle série, sous la direction de Sylvain LEDDA et Sophie VANDEN ABEELE-MARCHAL, Paris, Garnier Classiques, 2016, 197 pp.

Dans cette nouvelle série, le «Bulletin de l'association des amis de Vigny», qui a plus de quarante ans d'existence, s'ouvre par une préface de Sophie VANDEN ABEELE-MARCHAL ( $E E t$ l'inspiration ou la mort». Rire, dérision et ironie chez Vigny, pp. 19-29) qui exprime combien l'ironie chez Vigny et le rire lui-même sont mis au service d'une idée philosophique, d'une critique de type moraliste jugeant des grands moments historiques. Par exemple, celui de la terreur révolutionnaire dans Stello, avec le pouvoir despotique exercé par Saint-Just et Robespierre, et leur conception de la fonction des poètes dans la République. Dérision des dérisions: la Terreur va en arriver à guillotiner André Chénier. Une conception de la poésie guillotine la poésie. Leçon de l'Histoire: sous l'habit de l'éloquence politique s'exprime un despotisme.

Sylvain LEDDA rédige ensuite des Notes sur le rire chez Vigny (pp.31-39) On se fait ordinairement de cet auteur l'image d'un homme sérieux, grave et triste, ce qui semblerait donc exclure de son œuvre le rire et la bonne humeur, comme Anatole France le soutenait. L'article prouve que le rire n'est absent ni des lèvres de Vigny, ni de ses écrits, en grand lecteur et admirateur qu'il était de Molière et de Shakespeare. Vigny utilise toutes les palettes du rire, depuis l'insouciant jusqu'au cynique, sans dédaigner le franchement comique. Cette vérité devrait pouvoir nous réconcilier largement avec l'homme Vigny.

Puis Janette MC LEMAN-CARNIE propose Quelques remarques sur l'ironie et le coup de théâtre chez Vigny (pp.41-56) où apparaissent ses qualités de dramaturge. Il a le talent 
d'introduire un coup de théâtre, prenant ainsi le spectateur au dépourvu, comme le confirme Chatterton. L'influence des œuvres de Shakespeare sur sa manière dramaturgique apparaît à l'évidence. Mais Vigny a la délicatesse d'épargner au public français les images violentes et les expressions grossières du poète anglais. Pour cette raison, l'ironie chez lui perd quelque chose de l'intensité dramatique qu'elle a chez Shakespeare, lequel s'exprime sans contrainte, sans retenue aucune, alors que Vigny maintient une politesse encore attendue du public de son temps.

Valentina PONZETTO, avec "Quitte pour la peur", nuances d'ironie (pp. 57-72), démontre que l'ironie sous la plume de Vigny peut ne pas être satirique ou persiflante, mais plus retenue, comme s'il s'excusait de devoir présenter les situations avec ironie. C'est ce qu'André Jarry a cru pouvoir nommer son «ironie rose», dont cette comédie-proverbe est la parfaite illustration. Subtile, l'ironie teintée d'amertume, évite l'humour noir et le sarcasme. Sa portée est d'aider à tirer des leçons morales des situations ou des événements que Vigny a choisis de mettre en œuvre. Il s'agit d'une ironie littéraire, par une sorte de dissimulation comme le déclarait Cicéron. Enfin, l'ironie s'efface pour faire place à des effets de pur comique à l'imitation moliéresque, sans jamais disparaître pour autant.

5 Roselyne de VILLENEUVE se consacre à Indéfinis et ironie dans "Cinq-Mars" (pp. 73-96). En spécialiste du lexique linguistique, grammatical et rhétorique (syntagme, isolexisme etc...), elle fait comprendre à tout lecteur que les indéfinis utilisés par Vigny dans ce roman historique sont toujours à entendre dans un double sens, transformant l'indéfini quantitatif en son contraire ironique. Ainsi fait-il percevoir au lecteur le cynisme du cardinal de Richelieu par son usage de «quelques» pour désigner des hérétiques ou des ennemis dont il veut se débarrasser, suggérant leur insignifiance par rapport à l'intérêt supérieur de l'État, le «tout» qui lui importe seul; ces «quelques» ne sont pour lui que «plusieurs», son contraire ironique dans son esprit que Vigny nous désigne ainsi comme monstrueux. Cette «signature verbale de Richelieu», porteuse d'une ironie tragique, sature son discours, toujours constitué lui-même «de quelques mots vagues»: il est un locuteur parcimonieux, mais un acteur politique prodigue.

6 Anastasia SCEPI (L'arabesque dans "Stello", pp. 97-110), après avoir défini cette figure géométrique d'ornementation se défigurant elle-même de façon fantaisiste mais intentionnelle, nous fait entendre que Vigny se livre à des arabesques littéraires autour d'une idée ou d'un thème. Stello lui en semble la preuve et l'illustration: comme l'arabesque s'éloigne de façon excentrique de la figure géométrique initiale, Vigny pratique la broderie autour d'une idée, s'éloigne du centre de son idée pour mieux instruire son lecteur.

7 Avec Vigny épistolier pour l'amour de l'humanité (pp.111-135), Lise SABOURIN nous fait comprendre quel homme était vraiment Vigny, quelle était l'âme de ce poète philosophe. Elle l'étudie à travers sa Correspondance où il révèle ses deux visages. Le premier est celui d'un homme distingué, doté de toutes les bonnes manières, qui emploie les formules de politesse codées, mais en leur donnant une touche et une vivacité qu'elles n'ont pas toujours, faisant preuve d'humour, de piquant, mais aussi de sincérité totale et directe, sans détours. Le second est celui de la solitude et de l'éloignement causé par sa vie, notamment au Maine-Giraud, mais aussi à Paris, quand par exemple il ne veut même plus mettre les pieds à l'odéon pour assister aux représentations de ses œuvres. Il se retranche alors dans le rôle d'un conseiller, principalement auprès des femmes, afin qu'elles conservent le meilleur d'elles-mêmes: 
leur sensibilité. Il conçoit sa Correspondance comme relevant de la causerie pudique. Tel fut l'homme Vigny.

Le numéro se poursuit avec des «Varia». Antonia FONYI examine les rapports de Vigny, Mérimée et l'Histoire (pp. 139-154) dans Cinq-Mars et la Chronique du temps de Charles IX, selon leurs conceptions respectives du roman historique. Vigny romance la réalité des faits pour en dégager une haute signification morale, exemplaire du bien et du mal dans l'Histoire. En un mot: il veut éduquer plutôt qu'instruire. Mérimée réunit des anecdotes afin de proposer une peinture des caractères et des mœurs d'une époque, plus paysagiste. Esther PINON présente un manuscrit retrouvé dans le fonds de la maison de Victor Hugo: le premier jet des vingt-trois premiers vers de "Symétha", avec fac-similé de ce que Martine CONTENSOU a déchiffré et transcrit (pp. 155-167). Hugo confessait que son ode "Quiberon», qui avait fait pleurer Chateaubriand, lui semblait bien peu de choses en comparaison de «l'adorable Symétha» de Vigny, écrite en date du 31 mai 1820. C'est une invitation à apprécier l'inspiration et l'éloquence dont fait preuve notre poète dans cette élégie inachevée à la vierge de Lesbos, qui ne serait que prélude à une composition beaucoup plus ample inspirée de sources antiques (l'Iliade principalement). Sophie VANDEN ABEELE-MARCHAL présente un portrait inédit d'Alfred de Vigny par Adèle Hugo (pp. 169-180): l'épouse du grand homme aurait conçu le projet de consacrer un livre aux amis disparus de son mari, sous le contrôle de Sainte-Beuve, ce qui incite à estimer suspecte la spontanéité de ce portrait. Tel qu'il est, il ne manque cependant pas d'intérêt, le montrant comme un homme très ordonné, aux idées déterminées, dignes, dépourvues de mesquinerie, mais n'envisageant la vie que «par ses côtés décevants et amers» (pp.177-178), ce qui en effet semble révéler un jugement très partial sur sa personnalité profonde. Le bulletin se termine sur l'habituelle et utile «revue des autographes» pour 2014-2015 (pp. 181-189) assurée par Thierry BoDIN, l'évocation de la vie de l'association (pp. 191-193) par sa secrétaire générale Esther PINON, en cette année 2016 marquée par le décès de sa présidente d'honneur-fondatrice Christiane Lefranc (in memoriam par Lise SABOURIN, pp. 13-15). 